\title{
Effect of thermal exposure on microstructure and nano-hardness of broached Inconel 718
}

\author{
Zhe Chen ${ }^{1, a}$, Ru Lin Peng ${ }^{1}$, Pajazit Avdovic ${ }^{2}$, Jinming Zhou ${ }^{3}$, Johan Moverare ${ }^{1,2}$, Fredrik Karlsson ${ }^{2}$, and Sten Johansson ${ }^{1}$ \\ ${ }^{1}$ Division of Engineering Materials, Linköping University, 58183 Linköping, Sweden \\ ${ }^{2}$ Siemens Industrial Turbomachinery AB, 61283 Finspång, Sweden \\ ${ }^{3}$ Division of Production and Materials Engineering, Lund University, 22100 Lund, Sweden
}

\begin{abstract}
Inconel 718 is a high strength, heat resistant superalloy that is used extensively for components in hot sections of gas turbine engines. This paper presents an experimental study on the thermal stability of broached Inconel 718 in terms of microstructure and nano-hardness. The broaching process used in this study is similar to that used in gas turbine industries for machining fir-tree root fixings on turbine discs. Severe plastic deformation was found under the broached surface. The plastic deformation induces a work-hardened layer in the subsurface region with a thickness of $\sim 50 \mu \mathrm{m}$. Thermal exposure was conducted at two temperatures, $550{ }^{\circ} \mathrm{C}$ and $650{ }^{\circ} \mathrm{C}$ respectively, for $300 \mathrm{~h}$. Recrystallization occurs in the surface layer during thermal exposure at $550^{\circ} \mathrm{C}$ and $\alpha-\mathrm{Cr}$ precipitates as a consequence of the growth of recrystallized $\delta$ phases. More recrystallized grains with a larger size form in the surface layer and the $\alpha$-Cr not only precipitates in the surface layer, but also in the sub-surface region when the thermal exposure temperature goes up to $650^{\circ} \mathrm{C}$. The thermal exposure leads to an increase in nano-hardness both in the work-hardened layer and in the bulk material due to the coarsening of the main strengthening phase $\gamma^{\prime \prime}$.
\end{abstract}

\section{Introduction}

The use of Inconel 718 as a disc material in gas turbine engines has increased in recent years because it has good microstructural stability and can maintain high yield and high tensile strength at elevated temperature. The main strengthening particles in Inconel 718 are precipitates of the metastable $\mathrm{Ni}_{3} \mathrm{Nb} \gamma^{\prime \prime}$ phase with an ordered body centered tetragonal (BCT) lattice structure [1]. Rapid coalescence of $\gamma^{\prime \prime}$ and the transformation of $\gamma^{\prime \prime}$ to the stable orthorhombic $\delta$ phase can result in reduced mechanical properties above $650{ }^{\circ} \mathrm{C}$ [2]. The precipitation of $\alpha-\mathrm{Cr}$ and sigma after long-time thermal exposure at high temperature can be another factor that affects the mechanical properties [3].

Machinability is a term that refers to how easily a material can be machined to a desired shape with an acceptable surface finish [4]. It has always been a challenge when machining Inconel 718 due to its poor machinability [5-8]. High strength together with low thermal conductivity leads to increased cutting forces and severe heat generation in the cutting zone, thereby causing inevitable changes under the machined surface, especially in terms of microstructure, such as plastic deformation [9, 10]. The main problem that plastic deformation is known to cause is work hardening of the surface and the subsurface region because of excessive plastic strains. Some studies have shown the micro-hardness profiles of Inconel

\footnotetext{
${ }^{a}$ Corresponding author: zhe.chen@liu.se
}

718 after turning, and the drop from a higher surface hardness to a lower bulk material hardness is explained by the work hardening effect [11-13].

Although many comprehensive studies have already investigated on the microstructure and the work-hardened layer of Inconel 718 after machining under various cutting conditions, few papers detail the thermal stability of machined Inconel 718 in terms of microstructure and micro-hardness. When a metal is subjected to intensive plastic deformation, a large amount of deformation energy remains latent in the metal causing the instability of microstructure and a consequential change in microhardness, especially when the metal is heated. Inconel 718 is extensively used for components in hot sections of gas turbine engines. The components normally endure cyclic mechanical loadings as well as excessive thermal impact. In the case of thermal mechanical fatigue, cracks typically initiate at the surface and the crack growth behavior markedly depends on microstructure, strength and environment [14].

The primary objective of the present study is to investigate the effect of thermal exposure on the stability of microstructure and nano-hardness in broached Inconel 718. Nano-hardness gives the hardness value of a small volume of the material, thereby can be used to characterize different types of microstructures in metals. Broaching is commonly used in industry to machine components with complex geometries. The broaching operation used in this study is similar to that used in gas turbine industries for machining fir-tree root fixings for gas turbine

This is an Open Access article distributed under the terms of the Creative Commons Attribution License 4.0, which permits unrestricted use, distribution, and reproduction in any medium, provided the original work is properly cited. 
Table 1. Chemical composition (wt. \%) of Inconel 718 and heat treatment applied to the forging.

\begin{tabular}{|l|l|l|l|l|l|l|l|l|l|}
\hline \multirow{2}{*}{ Composition } & $\mathrm{Ni}$ & $\mathrm{Cr}$ & $\mathrm{Nb}$ & $\mathrm{Mo}$ & $\mathrm{Ti}$ & $\mathrm{Al}$ & $\mathrm{C}$ & $\mathrm{Si}$ & $\mathrm{Fe}$ \\
\cline { 2 - 7 } & 53.8 & 18.1 & 5.5 & 2.9 & 1 & 0.55 & 0.25 & 0.04 & Balance \\
\hline Heat treatment & \multicolumn{6}{|c|}{ Solution heat treatment at $970^{\circ} \mathrm{C}$ for $3.5 \mathrm{~h}$, first ageing at $720^{\circ} \mathrm{C}$ for $8 \mathrm{~h}$, second ageing at $620^{\circ} \mathrm{C}$ for $8 \mathrm{~h}$} \\
\hline
\end{tabular}

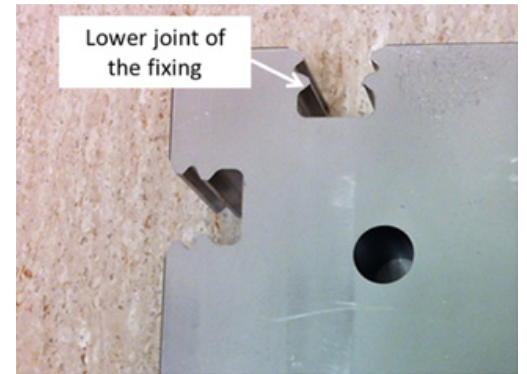

Figure 1. Broached fir-tree root fixings on the Inconel 718 forging.

blade mounting. Therefore, the study has an industrial importance for understanding the fatigue behavior in turbine discs.

\section{Experimental setups}

A heat treated Inconel 718 forging with size $200 \mathrm{~mm}$ in length $\times 200 \mathrm{~mm}$ in width $\times 50 \mathrm{~mm}$ in height was used for this study. The chemical composition of Inconel 718 and the heat treatment applied to the forging are summarized in Table 1. The broaching was carried out on a vertical broaching machine. Fir-tree root fixings for blade mounting were broached at the edge of the forging with semi-worn high speed steel tools $(65-67 \mathrm{HRC})$, oil coolant and with a fixed cutting speed of $v_{c}=3 \mathrm{~m} / \mathrm{min}$. The joint between the turbine blade and the disc usually represents the most critical area from the point of view of the static and fatigue approaches [15]. Therefore, all studies were conducted at the lower joint of the fir-tree root fixings, as shown in Fig. 1. Three specimens were cut from the forging in order to expose the broached surface of the lower joint. One was kept in the as-broached condition and the other two specimens were thermally exposed at $550{ }^{\circ} \mathrm{C}$ for $300 \mathrm{~h}$ and at $650^{\circ} \mathrm{C}$ for $300 \mathrm{~h}$ respectively followed by air cooling.

Cross-sections parallel to the broaching direction were mechanically polished for microstructural studies and nano-hardness measurements. The microstructural studies were performed by electron channeling contrast (ECC) imaging, electron backscatter diffraction (EBSD) mapping and energy-dispersive X-ray spectroscopy (EDX) mapping in a Hitachi SU-70 FEG-SEM (field emission gun - scanning electron microscope). ECC images can provide a sufficient resolution for analyzing deformation in highly deformed alloys. The presence of a local defect like a dislocation can either block the channeling of electrons, thereby scattering more electrons back, or open a channel to let electrons penetrate to a higher depth, reducing the number of back scattered electrons. Both effects can give a contrast of the dislocation. EBSD mapping was conducted in five sub-surface areas of
$80 \mu \mathrm{m}$ by $80 \mu \mathrm{m}$ stretching from the broached surface into specimen depth with a step length of $0.5 \mu \mathrm{m}$. In EBSD analysis, quantitative information about the lattice orientation for each measured point can be obtained from the mapping. The crystallographic misorientation within grains associated with plastic deformation between each two adjacent points was calculated subsequently. A misorientation angle within the range of $1^{\circ}$ and $10^{\circ}$ was defined as a low angle grain boundary (LAGB). The LAGB density reveals the intensity of local intragranular misorientations in material, thereby being widely used to quantify plastic deformation level in machined components $[10,16]$. X-ray diffraction with $\mathrm{Cr}-\mathrm{K} \alpha$ radiation was performed to identify the precipitates after thermal exposure. Nano-hardness depth profiles were measured from the broached surface to the bulk material with a step of $10 \mu \mathrm{m}$ in the polished cross-section. Five measurements were taken at each depth and an average was obtained. Each indentation was conducted by applying a load of $50 \mathrm{mN}$ with $30 \mathrm{~s}$ holding time.

\section{Results and discussion}

\subsection{Microstructural stability}

\subsubsection{As-broached specimen}

An ECC image showing the plastic deformation structure under the broached surface is presented in Fig. 2a. A thin surface layer (3-5 $\mu \mathrm{m})$ with an irresolvable microstructure forms during the broaching. It is believed that the formation of this layer is attributed to a combination of severe plastic deformation, high temperature generated at the machined surface and rapid cooling by coolant [17]. The sub-surface microstructure consists of elongated and sheared grain boundaries in the broaching direction and deformed grains with crossed slip bands. The deformed structure can be identified in the whole sub-surface region down to the bulk material. The change of LAGB density versus the depth under the broached surface is presented in Fig. 2b. The maximum LAGB density appears at the broached surface followed by a decrease with an increasing depth. The higher LAGB density in the subsurface region in comparison to that of the bulk material reveals an increasing plastic deformation level induced by the broaching. The deformation zone extends to a depth of $\sim 50 \mu \mathrm{m}$.

\subsubsection{Thermal exposure effect}

Figure $3 \mathrm{a}$ shows that after $300 \mathrm{~h}$ thermal exposure at $550^{\circ} \mathrm{C}$, the microstructure in the sub-surface region still retains the plastic deformation characteristics as observed previously in the as-broached specimen. The thermal exposure causes recrystallization and precipitation in the surface layer. Most of the recrystallized grains form at 

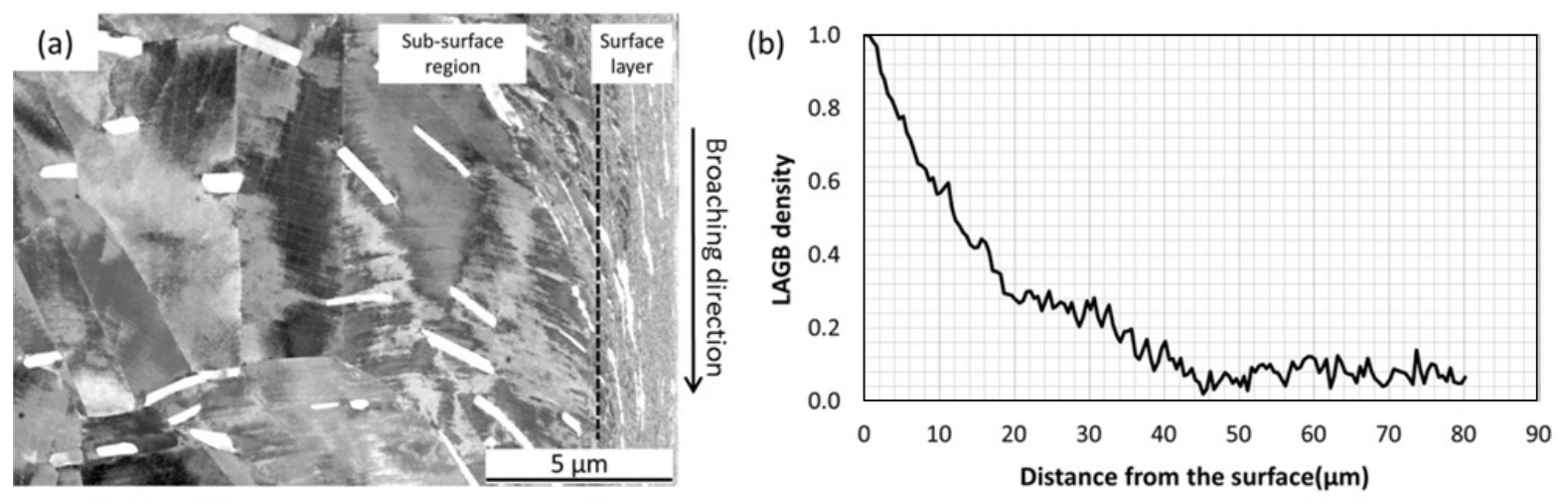

Figure 2. (a) An ECC image showing the machining-induced plastic deformation in the as-broached specimen; (b) The change of LAGB density versus the depth under the broached surface of the as-broached specimen.
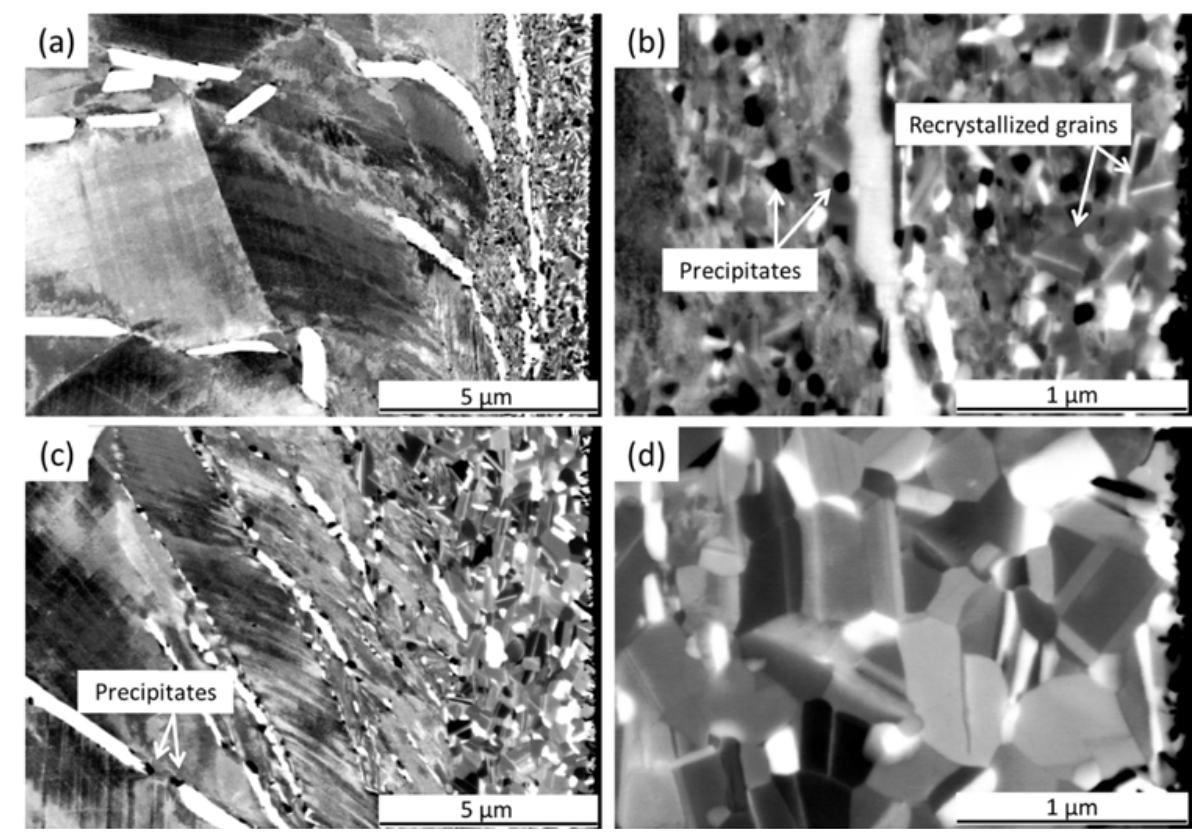

Figure 3. ECC images showing (a) the microstructural changes after $300 \mathrm{~h}$ thermal exposure at $550{ }^{\circ} \mathrm{C}$; (b) the recrystallization and the precipitation in the surface layer after $300 \mathrm{~h}$ thermal exposure at $550^{\circ} \mathrm{C}$; (c) the microstructural changes after $300 \mathrm{~h}$ thermal exposure at $650{ }^{\circ} \mathrm{C}$; (d) the growth of the recrystallized grains in the surface layer after $300 \mathrm{~h}$ thermal exposure at $650^{\circ} \mathrm{C}$.

the broached surface, whereas a few of them with a smaller size emerge inside the surface layer, as shown in Fig. 3b. The mechanism responsible for recrystallization in a machined component during thermal exposure can be described by the storage of large energy induced by the plastic deformation [18]. The irresolvable microstructure and the highest LAGB density as shown previously in Fig. 2 have indicated that the surface layer where the recrystallization occurs endures the most severe plastic deformation during the broaching. Recrystallized metals normally have low strength but high ductility since the number of dislocations is greatly reduced. Therefore, the recrystallization in the surface layer after thermal exposure tends to soften the material and give a lower nano-hardness value at the broached surface. Small black precipitates which normally form in the vicinity of the $\delta$ phase also can be found in the surface layer after $300 \mathrm{~h}$ thermal exposure at $550{ }^{\circ} \mathrm{C}$ as shown in Fig. 3b. Figure $3 \mathrm{c}$ indicates that the black precipitates not only emerge in the surface layer, but also form in the sub-surface region when the thermal exposure temperature goes up to $650^{\circ} \mathrm{C}$. Meanwhile, more recrystallized grains nucleate and grow in size in the surface layer after $300 \mathrm{~h}$ thermal exposure at $650{ }^{\circ} \mathrm{C}$, as shown in Fig. 3d.

EDX mapping was conducted on the small black precipitates after $300 \mathrm{~h}$ thermal exposure at $650{ }^{\circ} \mathrm{C}$, as shown in Fig. 4a. High content of $\mathrm{Cr}$ can be detected in the area where black particles precipitate revealing $\alpha$ $\mathrm{Cr}$ identification which is in agreement with the XRD diffraction, as shown in Fig. 4b. The EDX mapping also shows that the $\alpha-\mathrm{Cr}$ precipitates at the location adjacent to the $\mathrm{Ni}$ and $\mathrm{Nb}$ rich $\delta$ phase. $\mathrm{Z}$. Bi et al. have studied the formation of $\alpha$-Cr precipitates in Inconel 718 after thermal exposure at high temperature [19]. $\mathrm{Cr}$ segregation must exist where $\alpha$-Cr precipitates. The formation and growth of $\delta$ phase reject $\mathrm{Cr}$ atoms, thereby causing $\mathrm{Cr}$ accumulation in the vicinity. $\alpha$-Cr precipitates normally nucleate on the (010) plane of $\delta$ phase and grow into the austenitic matrix 

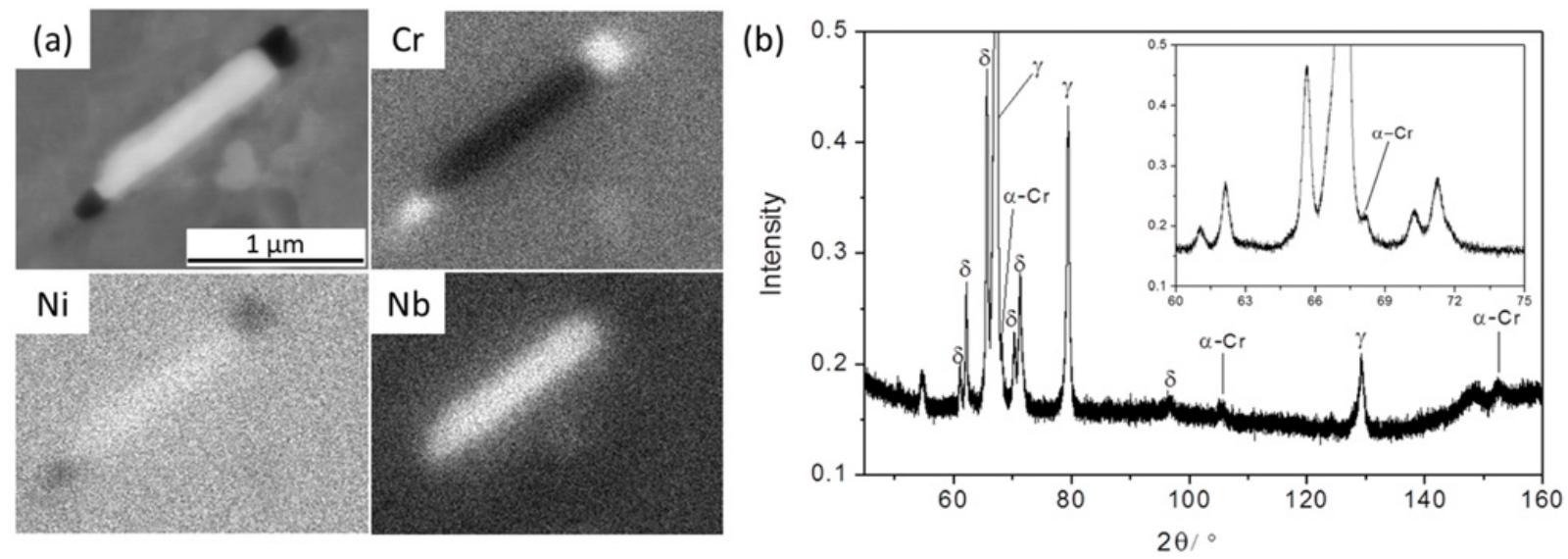

Figure 4. (a) EDX mapping around the black precipitates in the specimen after $300 \mathrm{~h}$ thermal exposure at $650{ }^{\circ} \mathrm{C}$; (b) $\mathrm{XRD}$ diffraction pattern identifying the existence of $\alpha$-Cr precipitates after $300 \mathrm{~h}$ thermal exposure at $650{ }^{\circ} \mathrm{C}$.

following crystallographic orientation relationships with the $\delta$ phase.

After $300 \mathrm{~h}$ thermal exposure at $550{ }^{\circ} \mathrm{C}$, the high deformation energy stored in the surface layer causes the recrystallization of $\delta$ phase. $\mathrm{Cr}$ segregates in the vicinity of the growing recrystallized $\delta$ phase leading to the precipitation of $\alpha-\mathrm{Cr}$ phase. When the temperature increases to $650{ }^{\circ} \mathrm{C}$, the growth of $\delta$ phase occurs in the sub-surface region resulting in continued rejection of $\mathrm{Cr}$. Therefore, $\alpha-\mathrm{Cr}$ precipitates can be observed not only in the recrystallization zone, but also in the subsurface region after $300 \mathrm{~h}$ thermal exposure at $650^{\circ} \mathrm{C}$, as shown in Fig. 3c. A. Oradei-Basile et al. have carried out the TTT diagram study for wrought Inconel 718, and found that $\alpha$-Cr precipitates normally form after long term exposure over $1000 \mathrm{~h}$ at $650^{\circ} \mathrm{C}$ [20]. $\alpha$ - $\mathrm{Cr}$ precipitation is a diffusion controlled process, thus the mobility of $\mathrm{Cr}$ in the matrix is crucial to the formation of $\alpha-\mathrm{Cr}$ precipitates from the point of view of the growth kinetics. The large number of dislocations induced by the broaching can enhance the mobility of $\mathrm{Cr}$ atoms and vacancies as diffusion pipes [21], thereby shortening the exposure time required for the nucleation and growth of $\alpha$-Cr precipitates. Studies have proposed that the formation and growth of $\alpha$-Cr precipitates in long term exposed Inconel 718 at high temperature is partly responsible for the severe drop in impact strength, but the change in micro-hardness is mainly associated with the coalescence of $\gamma^{\prime \prime}$ and the transformation of $\gamma^{\prime \prime}$ to $\delta$ phase [22].

\subsection{Nano-hardness}

\subsubsection{Work-hardened layer}

In this study, since the surface layer is too thin to be measured and the edge effect can not be avoided when the indenter moved to the area close to the broached surface, no reliable nano-hardness data was obtained in the surface layer. Figure 5 reveals that a higher nano-hardness value can be measured in the sub-surface region of the as-broached specimen. The nano-hardness drops from the maximum value $(\sim 6.3 \mathrm{GPa})$ to the bulk hardness $(\sim 5.7 \mathrm{GPa})$ within a depth of $\sim 50 \mu \mathrm{m}$. The thickness of the layer with the higher nano-hardness

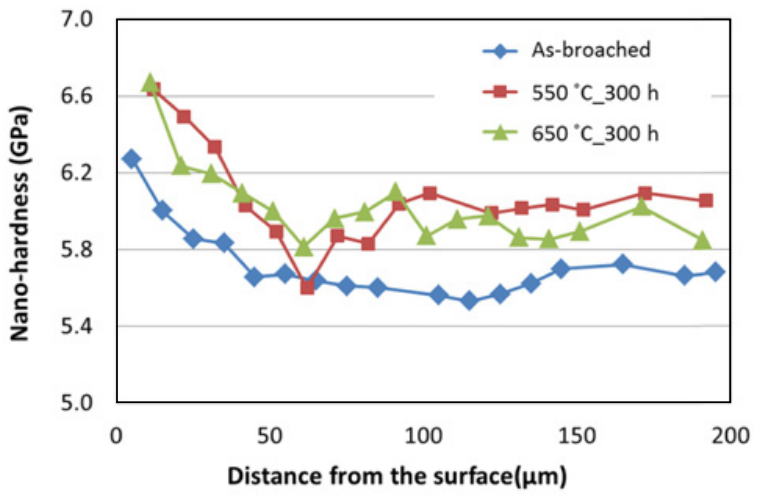

Figure 5. Nano-hardness depth profiles under the broached surface.

value is close to the deformation depth as obtained previously from Fig. $2 b$, showing the broaching-induced plastic deformation greatly contributes to the hardening effect. The increase in hardness during machining can be explained by various hardening mechanisms such as deformation-induced hardening, precipitation hardening and phase transformation hardening etc. depending on the type of the machined material. For Inconel 718 alloys, because of the work-hardening tendency of nickel alloys under excessive strain loading, a workhardened layer easily forms in response to the machininginduced deformation in the sub-surface region [8]. Studies have also revealed that in machining Inconel 718 the work hardening behavior and the degree (or depth) of work hardening are mainly dependent on plastic deformation [23].

\subsubsection{Thermal exposure effect}

The thermal exposure creates higher nano-hardness values under the broached surface as shown in Fig. 5. It is worth noting that the nano-hardness in the work-hardened layer and in the bulk material both increase after thermal exposure and the extent of their increase is almost the same. For a work-hardened layer that is composed of deformed grains with a large number of tangled 

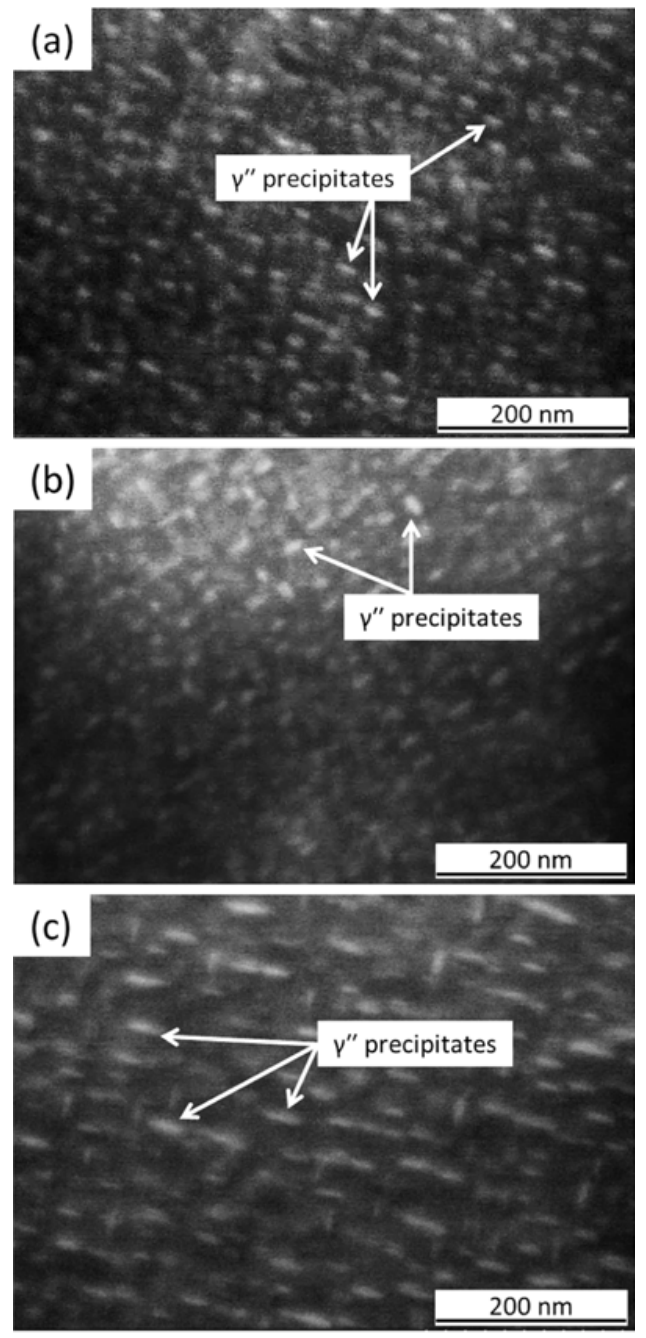

Figure 6. The main strengthening phase $\gamma^{\prime \prime}$ in (a) the as-broached specimen; (b) the thermally exposed specimen at $550^{\circ} \mathrm{C}$ for $300 \mathrm{~h}$; (c) the thermally exposed specimen at $650^{\circ} \mathrm{C}$ for $300 \mathrm{~h}$.

dislocations, the additional thermal energy can permit the dislocations to glide and climb causing a recovery process which could soften the material by the partial elimination of the dislocations. However, Inconel 718 is a typical alloy with low stacking fault energy where presence of solute atoms and precipitates reduce the mobility of dislocations thereby restricting the recovery process.

Hardening of Inconel 718 is mainly dependent on $\gamma^{\prime \prime}$ precipitation which gives coherency strains in the alloy. During isothermal aging, the hardening effect initially increases as a result of the increase of $\gamma^{\prime \prime}$ precipitates in volume fraction. As the precipitates coarsen, an optimum size exists with respect to hardness, and further coarsening has been related to a decrease in the hardening effect [1]. In this study, SEM investigations on $\gamma^{\prime \prime}$ precipitates were conducted in the work-hardened layer of the as-broached specimen as well as the thermally exposed specimens. Similar coarsening behavior of $\gamma^{\prime \prime}$ precipitates can be expected in the bulk material because of the nearly same increase of nano-hardness in the work-hardened layer and in the bulk material after thermal exposure. It indicates that the dislocations induced by the broaching have a very slight effect on the coarsening behavior of $\gamma^{\prime \prime}$ precipitates.

Figure 6a shows disc shaped $\gamma^{\prime \prime}$ precipitates in the as-broached specimen. The coarsening of $\gamma^{\prime \prime}$ precipitates follows the Lifshitz-Slyozov-Wagner theory [24,25] with a volume diffusion-controlled growth. During thermal exposure at $550{ }^{\circ} \mathrm{C}$, the diffusion rate is weak and the growth occurs rather slowly as shown in Fig. 6b; consequently, the $\gamma^{\prime \prime}$ precipitates could increase in size but maintain coherency with the matrix. The increase in nanohardness after $300 \mathrm{~h}$ thermal exposure at $550{ }^{\circ} \mathrm{C}$ reveals that the slow coarsening gives an enhanced coherent strengthening effect in the alloy. After $300 \mathrm{~h}$ thermal exposure at $650{ }^{\circ} \mathrm{C}$, the temperature is sufficiently high to accelerate the diffusion and to induce a significant coarsening of $\gamma / \prime$ precipitates as shown in Fig. 6c. At $650{ }^{\circ} \mathrm{C}$, the $\gamma^{\prime \prime}$ precipitates increase into the optimum size which gives the maximum nano-hardness in a short time due to the fast diffusion. The alloy is over-aged after 300 $\mathrm{h}$ thermal exposure at $650{ }^{\circ} \mathrm{C}$ since there is no continued increase in nano-hardness in comparison with that at $550{ }^{\circ} \mathrm{C}$, as shown in Fig. 5. Studies have indicated that for a $\gamma^{\prime \prime}$ diameter lower than $50 \mathrm{~nm}$, the coherency between the $\gamma^{\prime \prime}$ precipitates and the matrix still exists [26]. Although the alloy is over-aged, the $\gamma^{\prime \prime}$ precipitates do not loss the coherency and the strengthening effect remains giving higher nano-hardness values in the alloy in comparison with that of the as-broached specimen.

\section{Conclusions}

The effect of thermal exposure on the surface integrity, in terms of microstructure and nano-hardness, has been investigated in broached Inconel 718. The broaching process used in this study is similar to that used in gas turbine industries for machining fir-tree root fixings on turbine discs. The conclusions can be drawn as follows:

- The broaching operation causes severe plastic deformation in the surface layer, followed by a gradient of deformation reducing in depth. A workhardened layer with a thickness of $\sim 50 \mu \mathrm{m}$ forms under the broached surface mainly attributed to the machining-induced plastic deformation.

- Stored deformation energy under the broached surface makes the microstructure instable during thermal exposure. Recrystallization occurs in the surface layer during thermal exposure at $550^{\circ} \mathrm{C}$ and $\alpha$-Cr precipitates as a consequence of the growth of recrystallized $\delta$ phases. More recrystallized grains with a larger size form in the surface layer and the $\alpha$-Cr not only precipitates in the surface, but also in the sub-surface region when the thermal exposure temperature goes up to $650{ }^{\circ} \mathrm{C}$. The high density of dislocations in the sub-surface region induced by the broaching contributes to improving the mobility of $\mathrm{Cr}$ atoms in the matrix, thereby shortening the thermal exposure time for the formation of $\alpha-\mathrm{Cr}$ precipitates.

- The thermal exposure leads to an increase in nano-hardness both in the work-hardened layer and in the bulk material. The presence of solute 
atoms and precipitates in Inconel 718 reduce the mobility of dislocations, thereby hindering the recovery process. The coarsening of the main strengthening phase $\gamma^{\prime \prime}$ is responsible for the higher nano-hardness after the thermal exposure. The dislocations induced by plastic deformation during the broaching have a very slight effect on the coarsening behavior of $\gamma^{\prime \prime}$ precipitates.

Agora Materiae and Strategic Faculty Grant AFM (Faculty grant SFO-MAT-LIU\#2009-00971) at Linköping University are acknowledged. The assistance work with sample preparation by Ms. Annethe Billenius is appreciated. The scholarship provided by the China Scholarship Council for Mr. Zhe Chen is also greatly appreciated.

\section{References}

[1] D. Paulonis, J. Oblak, D. Duvall. Trans. ASM, 62, 611 (1969)

[2] J.F. Barker, J.F. Radavich, E.W. Ross. J. Met., 22, 31 (1970)

[3] W. Gailian, W. Cuiwei, Z. Maicang, D. Jianxin, X. Xishan, J. Radavich, B.A. Lindsley, G. Shen. Mater. Sci. Eng. A, 358, 71 (2003)

[4] E.O. Ezugwu. Int. J. Mach. Tool. Manuf., 45, 1353 (2005)

[5] I.A. Choudhury, M.A. El-Baradie. J. Mater. Process. Technol., 77, 278 (1998)

[6] R. Arunachalam, M.A. Mannan. Mach. Sci. Technol., 4, 127 (2000)

[7] D.G. Thakur, B. Ramamoorthy, L. Vijayaraghavan. Int. J. Adv. Manuf. Technol., 45, 421 (2009)

[8] D. Ulutan, T. Ozel. Int. J. Mach. Tools Manuf., 51, $250(2011)$
[9] M.R. Shankar, R. Verma, B. Rao, S. Chandrasekar, W. Compton, A. King, K. Trumble, Metall. Mater. Trans. A, 38, 1899 (2007)

[10] M. Imran, P.T. Mativenga, A. Gholinia, P.J. Withers. Int. J. Adv. Manuf. Technol., 55, 465 (2011)

[11] E. Ezugwu, J. Bonney, D. Fadare, W. Sales. J. Mater. Process. Technol., 162, 609 (2005)

[12] E. Ezugwu, S. Tang. J. Mater. Process. Technol., 55, $63(1995)$

[13] A. Sharman, J. Hughes, K. Ridgway. Mach. Sci. Technol., 8, 399 (2004)

[14] J. Pedron, A. Pineau. Mater. Sci. Eng., 56, 143 (1982)

[15] L. Witek. Eng. Fail. Anal., 13, 9 (2006)

[16] J.M. Zhou, V. Bushlya, R.L. Peng, J.E. Stahl. App. Mech. Mater., 117, 1681 (2012)

[17] B. Griffiths. J. Tribol., 109, 525 (1987)

[18] M.B. Bever, D.L. Holt, A.L. Titchener. Prog. Mater. Sci., 17, 5 (1973)

[19] Z. Bi, J. Dong, M. Zhang, L. Zheng, X. Xie. Inter. J. Miner. Metall. Mater., 17, 312 (2010)

[20] A. Oradei-Basile, J.F. Radavich. Superalloys 718, 625 and Various Derivatives, 325 (1991)

[21] G. Love. Acta Metall. 12, 731 (1964)

[22] X. Xie, G. Wang, J. Dong, C. Wu, J. Radavich, G. Shen, B.A. Lindsley. Superalloys 718, 625 and Various Derivatives, 399 (2001)

[23] R. Pawade, S.S. Joshi, P. Brahmankar. Int. J. Mach. Tool. Manuf. 48, 15 (2008)

[24] I.M. Lifshitz, V.V. Slyozov. J. Phys. Chem. Solids, 19, 35 (1961)

[25] C. Wagner. Zeitschrift für Elektrochemie, Berichte der Bunsengesellschaft für physikalische Chemie, 65, 581 (1961)

[26] A. Devaux, L. Nazé, R. Molins, A. Pineau, A. Organista, J. Guédou, J. Uginet, P. Héritier. Mater. Sci. Eng. A, 486, 117 (2008) 